\title{
Commentary: Do we have the right combatants? Should it be minimally invasive surgery versus therapy that removes no lymph nodes?
}

\author{
Robert J. Cerfolio, MD, MBA, FACS, FCCP
}

\author{
From the Department of Cardiothoracic Surgery, New York University, New York, NY. \\ Disclosures: Dr. Cerfolio discloses relationships with AstraZeneca, Bard Davol, Bovie Medical Corporation, \\ C-SATS, ConMed, Covidien/Medtronic, Ethicon, Fruit Street Health, Google/Verb Surgical, Intuitive Surgical, \\ KCI/Acelity, Myriad Genetics, Neomend, Pinnacle Biologics, ROLO-7, Tego, and TransEnterix. \\ Received for publication July 1, 2019; accepted for publication July 4, 2019; available ahead of print Sept 5, 2019. \\ Address for reprints: Robert J. Cerfolio, MD, MBA, FACS, FCCP, Department of Cardiothoracic Surgery, New \\ York University Langone Medical Center, 550 1st Ave, 15th Floor, New York, NY 10016 (E-mail: Robert. \\ Cerfolio@nyumc.org). \\ J Thorac Cardiovasc Surg 2019;158:1467-8 \\ $0022-5223 / \$ 36.00$ \\ Copyright (C) 2019 by The American Association for Thoracic Surgery \\ https://doi.org/10.1016/j.jtcvs.2019.07.004
}

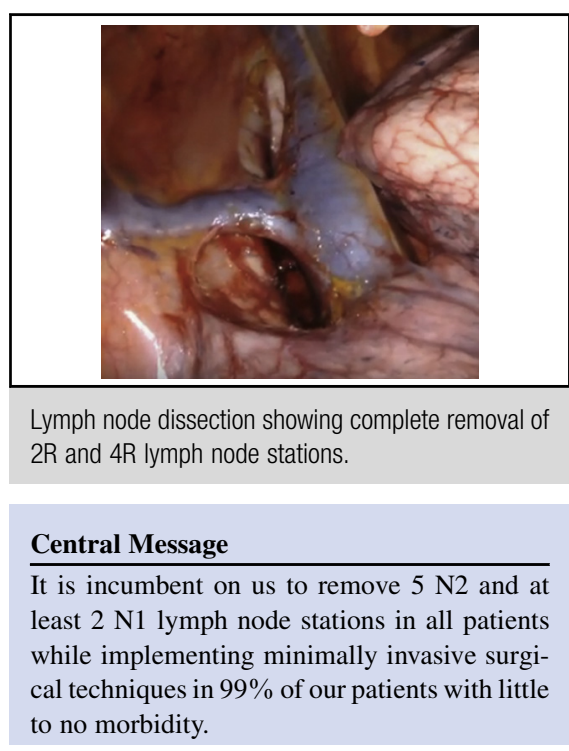

See Article page 1457.
In this issue of the Journal, Kneuertz and associates ${ }^{1}$ have reported a 2-institution study comparing lymph node upstaging by means of different surgical platforms: thoracotomy, video-assisted thoracoscopic surgery (VATS), and robotic surgery. The study is well done, and the data and statistics are also well done; however, the question asked cannot be answered by this study, nor will it be by any study soon. The reason is simple-the degree of lymph node removal during thoracic cancer surgery comes down to the thoracic surgeon's mind-set more so then the platform he or she chooses for surgery. Robotics probably makes it easier, but this is hard to prove. Surgeons are voting with their feet. Robotics has quickly surpassed VATS in hospitals that offer both, but most across the world still cannot afford robotics-yet.

The study itself has flaws. Those who prefer VATS will quickly expose them. Those inclined towards robotics will argue this study shows that a robotic platform allows easier lymph node dissection, especially in the subcarinal station in the left side of the chest. Time, as well as this study, will show that robotics offers a real advantage in the hands of most thoracic surgeons; however, this may not be the most pressing clinical question. What may matter more on this issue are the questions of how many patients have their disease upstaged after maximal clinical lymph node staging and of what the value to patients is. Maximal clinical staging means that all patients get the most advanced computed tomographic scanning and integrated positron emission testing with computed tomography, and selected patients get endoscopic bronchial ultrasound or mediastinoscopy. Unfortunately, these 3 staging initiatives were not routinely performed or applied in a standardized manner in the study of Kneuertz and associates. ${ }^{1}$ As minimally 
anatomic (not wedge, except in the case of a pure ground glass opacity) resection that is appropriate, use minimally invasive surgical techniques for $99 \%$ of our patients, and provide little to no morbidity with a 2-day hospital stay. Until we all do this consistently, we fail to actualize the true benefit of surgery. For all these reasons, I appreciate the well-done study by Kneuertz and colleagues ${ }^{1}$ and congratulate them on this important article. I wonder, however, are the correct combatants in the ring? The better question may be this: What is the benefit that we offer as surgeons (other than more complete molecular tumor analysis) relative to therapy that does not removal or sample any mediastinal or hilar lymph nodes?

\section{Reference}

1. Kneuertz PJ, Cheufou DH, D'Souza DM, Mardanzai K, Abdel-Rasoul M, Theegarten D, et al. Propensity-score adjusted comparison of pathologic nodal upstaging by robotic, video-assisted thoracoscopic, and open lobectomy for nonsmall cell lung cancer. J Thorac Cardiovasc Surg. 2019;158:1457-66.e2. 